\title{
THE EFFECT OF EXTRACTIVES ON ACOUSTICAL PROPERTIES OF PERSIAN SILK WOOD (Albizia julibrissin)
}

\author{
Farzin Farvardin ${ }^{1}$, Mehran Roohnia ${ }^{1, \wedge}$, Amir Lashgari ${ }^{1}$
}

\begin{abstract}
It was previously reported that extractives from Pernambuco wood (a species from Leguminosae family, native to South America) are positive for acoustical performance of wood. Thus the present study set to investigate the effect of extraction in hot water and ethanol/acetone mixture on acoustical properties of Persian silk wood (Albizia julibrissin, a species from Leguminosae family, native to Iran). Contactless forced flexural vibration on both freeends of beams was performed on thin small specimens before and after extraction. Results showed that the extractive components soluble in hot water were positively useful to acoustical properties because removing these extractives reduced the acoustic property of the wood. Raw wood from Persian silk tree based on a combination of studied acoustical characteristics has theoretically the potential to be applied in violin backs and ribs.
\end{abstract}

Keywords: Acoustic, Leguminosae, musical instrument, Pernambuco, Persian silk wood, vibration.

\section{INTRODUCTION}

Iranian musical instrument technology, an experience-based, traditional knowledge, prefers tone woods i.e. mulberry, maple, and walnut; but after some special hydrothermal treatments (Roohnia et al. 2011, Segolpayegani et al. 2012). Nowadays it has been revealed that hot water extraction of wood during traditional hydrothermal treatment, may withdraw some compounds which are not considered as stress supporting material in lignocellulose micro-structure. Here, some mechanical-acoustical properties of wood is defined; Damping due to radiation or namely sound radiation coefficient is an acoustical characteristic that depends on longitudinal modulus of elasticity and density (Rujinirun et al. 2005, Wegst 2006, Tsoumis 1991).

$$
K=\sqrt{\frac{E_{l}}{d^{3}}}
$$

In which $K$ is sound radiation coefficient in $\mathrm{m}^{4} / \mathrm{kg} . \mathrm{s}, E_{l}$ is longitudinal modulus of elasticity in $P a$, and $d$ corresponds to density in $\mathrm{kg} / \mathrm{m}^{3}$. There is a definition in reverse relationship with the former concept that is called damping $(\tan \delta)$ due to internal friction (Wegst 2006). Smaller damping due to internal friction means that the vibration lasts for a longer period of time. Damping due to internal friction is evaluated from logarithmic decrement in attenuation of vibration or from band-width in frequency domain (Bodig and Jayne 1993). Increases in sound radiation coefficient and/or decreases in damping due to internal friction totally appear in the concept of acoustical converting efficiency (ACE) (Yano and Minato 1993, Yasuda and Minato 1994, Rujinirun 2005, Brémaud 2012). This property is restored within this paper for indicating the acoustical property of wood;

$$
A C E=\frac{K}{\tan \delta}
$$

\footnotetext{
${ }^{1}$ Department of Wood and Paper Science and Technology, College of Agriculture and Natural Resources, Karaj Branch, Islamic Azad University, Moazen BLVD, Rajaeeshahr, Karaj, Iran. • Corresponding author: mehran.roohnia@kiau.ac.ir Received: 22.06.2014 Accepted: 02.06.2015
} 
Mechanical performance of wood mainly comes from its micro-structural materials i.e. cellulose and lignin in shape of fibers, rays, vessel element groups, joined together using a mortar known as lignin; however, extractives are mostly concentrated in cellular cavities without any dedication of structural reinforcement (Sjöström 1993). As an overview, the presence of such extractives do not result in strengthening the modulus of elasticity but may increase the density due to increases in mass without a significant change in volume of the specimen; perhaps, concerns remain due to swelling or shrinkages as well as shifts in equivalent moisture content of extracted or impregnated wood. So, extraction of such compounds will theoretically improve the sound radiation coefficient.

The above mentioned behavior fades when the extractives come to partly contribute to the structural bonds in wood. In this condition, the extraction may decrease (instead of increase) the mechanical and acoustical property of wood. This phenomenon, although, in lower quantities than cell wall constitutive polymers, is even reported in previous studies. To name an example, extractives of wood from Pernambuco (Caesalpinia echinata or Guilandina echinata) have previously been introduced (Matsunaga et al. 1999, Matsunaga et al. 2000a-b, Alves et al. 2008, Segolpayegani et al. 2012). It has been shown that the mechanical and acoustical properties of wood from Pernambuco weaken after extraction. It has been also shown that the mechanical and acoustical properties of wood increase after impregnation with extractive compounds of Pernambuco. So, the extractives from Pernambuco must have a positive effect on the acoustical properties of wood. Searching for a species showing a similar characteristic, encouraged the authors to examine all native species that might be similar. From the Leguminosae family (Pernambuco belongs to), the first choice was Persian silk wood (Albizia julibrissin).

Albizia julibrissin is a species of tree, native to southwestern and eastern Asia. The specific epithet julibrissin might be a corruption of the Persian word 'gul-i-abrisham' which means 'silk flower'. The species is supposed to be "similar to Pernambuco" because it belongs to the Leguminosae family. Indeed, there are several species of Leguminosae and they do not all share similar properties. Furthermore, Albizia genus belongs to sub-family Mimosoideae, whereas Caesalpinia genus (to which belongs Pernambuco wood) is part of the Caesalpiniodeae sub-family. Meanwhile, other Iranian tone woods that were not from Leguminosae were previously investigated; Roohnia et al. 2007, studied the Iranian stands of Arizona cypress, later in 2011, then after, Segolpayegani et al. 2012, studied the acoustic properties of Mulberry wood (used in Iranian traditional musical instruments) in terms of extractives. Roohnia et al. 2015, reported the acoustical performance of Maple wood before and after extraction. Other than Iranian native species, Minato et al. 1997, studied the vibrational properties of wood impregnated with extractives of some species of Leguminosae. Sakai et al. 1999, identified the effects of impregnation of simple phenolic and natural polycyclic compounds on physical properties of wood. Obataya et al. 1999, studied the effects of water-soluble extractives on the acoustic properties of reed (Arundo donax). In 2001, they reported the influence of moisture content on the vibrational properties of hematoxylin-impregnated wood. Minato et al. 2010, reported the effect of extractives on vibrational properties of Muirapiranga (Brosimun sp.). Brémaud et al. 2010, studied the effect of extractives on acoustical properties of African Padauk.

Persian silk wood has been chosen as the testing species from Leguminosae in this approach, not only for its probable similarities to Pernambuco, but also for its abundance and availability in Iran and, after all, this approach is still in progress to achieve a good knowledge of other Iranian native woods in acoustic applications by the present research laboratory. Given that data on acoustical properties of wood biodiversity are still insufficient, each new information on a given species would be useful. 


\section{MATERIALS AND METHODS}

Sampling was done from a $\log$ (diameter: $35 \mathrm{~cm}$ ) of Persian silk (Albizia julibrissin Durazz.) tree (harvested at Hyrcanian forests near the Caspian Sea). Specimens with nominal dimensions of $150 \times 14 \times 2 \mathrm{~mm}^{3}(\mathrm{~L} \times \mathrm{R} \times \mathrm{T})$ were prepared in accordance with the international standard, ISO3129 (visually clear, straight grain, without any defect, and avoiding the juvenile and/or reaction wood) and kept for at least two weeks in a climatic chamber in $65 \pm 5 \%$ relative humidity and $21 \pm 1^{\circ} \mathrm{C}$ temperature until the mass of the specimens were stabilized. Totally 13 pieces passed the qualifications of soundness after acclimatization and were considered for further examinations.

Contactless forced flexural vibration on both free-ends of beams was conducted to evaluate the mechanical properties of the specimens, namely, longitudinal modulus of elasticity and damping due to internal friction. Sound radiation coefficient was calculated using equation 1, taking into account the longitudinal modulus of elasticity and stabilized density. Euler-Bernoulli's elementary theory of flexural vibration (Bodig and Jayne 1993, Brancheriau and Bailleres 2002) and logarithmic decrement of sound attenuation were used to evaluate the longitudinal modulus of elasticity and damping due to internal friction, respectively from the $1^{\text {st }}$ mode of flexural vibration (Bodig and Jayne 1993).

Extraction scenario included three periods of hot water extraction (W1 to 3) followed by three periods of ethanol/acetone extraction (AA1 to 3) in a Soxhlet setup. Each period of extraction was continued for 8 hours. Mass reduction and acoustical changes were monitored after each period of extraction on stabilized specimens. Equivalent moisture content of extracted specimens after repeated stabilizations was concerned and controlled. After each step, the drying defects were also concerned and the stabilization procedure was controlled very gently.

Extraction in the form of mass decrease is studied besides the changes of introduced acoustic parameters. Then the scatter plots of damping due to internal friction versus radiation are shown and analyzed.

Usually, organic solvents extractions are applied prior to hot water. But, here the extraction has been started by the hot water. It is because of the simulation of a traditional attitude of Iranian luthiers to soak the wood in warm water first for a certain period of time, before instrument making, to achieve a better acoustical property.

\section{RESULTS AND DISCUSSION}

After each extraction step, some extractive components are removed where, at constant moisture content, mass decreases consecutively. The consecutive mass decrease for the specimens of this study is shown in figure 1 .

As the stabilized equivalent moisture content of the specimens remained relatively constant, the extraction steps could be indicated in the form of mass reduction. At the $3^{\text {rd }}$ step of hot water extraction, there were few amounts of extractive solubles in hot water, but after application of ethanol/acetone at the $4^{\text {th }}$ step, the rest quantity of the extractive was removed. For the next extraction steps, there was not any obvious change in the mass of the specimens. Table 1 shows the mean values of the measured properties of untreated wood.

Table 1. The mean values of the measured properties of untreated specimens.

\begin{tabular}{ccccccc} 
Property & $\begin{array}{c}\text { Mass } \\
(\mathbf{g})\end{array}$ & $\begin{array}{c}\text { Density } \\
\left(\mathbf{k g} / \mathbf{m}^{\mathbf{3}}\right)\end{array}$ & $\begin{array}{c}\text { Modulus } \\
\text { of } \\
\text { elasticity } \\
\mathbf{( G P a )}\end{array}$ & $\begin{array}{c}\text { Sound } \\
\text { radiation } \\
\text { coefficient } \\
\left(\mathbf{m}^{\mathbf{4}} / \mathbf{k g . s}\right)\end{array}$ & $\begin{array}{c}\text { Damping } \\
\text { due to } \\
\text { internal } \\
\text { friction }\end{array}$ & $\begin{array}{c}\text { Acoustic } \\
\text { conversion } \\
\text { efficiency } \\
\left(\mathbf{m}^{\mathbf{4}} / \mathbf{k g . s}\right)\end{array}$ \\
\hline Mean Value & 2,037 & 0,47 & 4,93 & 6,90 & 0,013 & 547,50 \\
\hline STDEV & 0,329 & 0,06 & 1,1 & 0,89 & 0,001 & 96,74
\end{tabular}


Density changes in extraction scenario are shown in Figure 2. Density depends on the stabilized volume other than the mass of the specimens. That is why there are some differences for the histograms of density. Stabilized density is the factor that influences the sound radiation coefficient (Eq1). A decrease in density (if the modulus of elasticity remains constant) results in greater sound radiation coefficient.

After each step of hot water extraction (Figure 3), however density is reduced successively and sound radiation coefficient is reduced unexpectedly. The idea that extraction reduces the modulus of elasticity is strengthening here for the hot water soluble extractive components. Considering this behavior, it is assumed that the hot water soluble extractive components of Albizia julibrissin behave similar to that of Guilandina echinata. These kinds of extractive components seem to be useful for the acoustical property of wood.

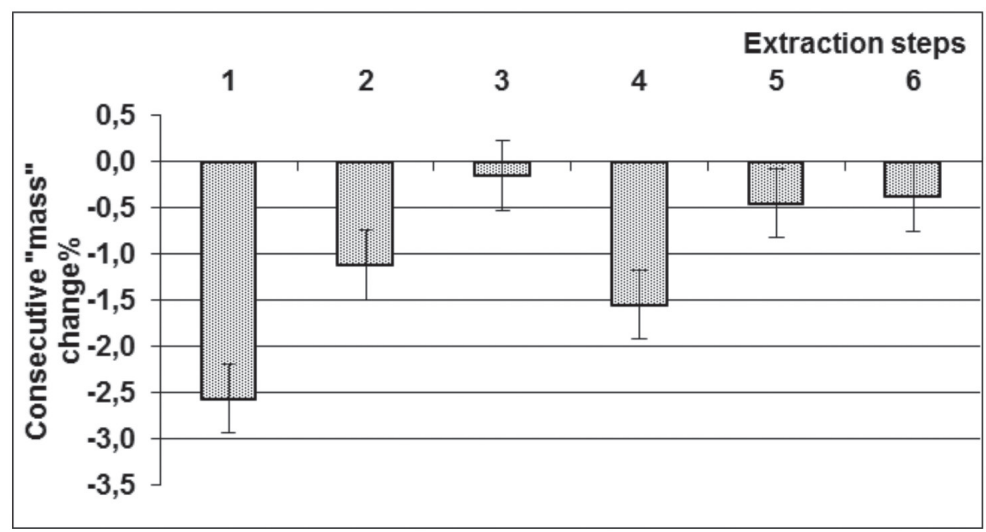

Figure 1. Consecutive mass change after each consecutive extraction step. 1,2 , and 3 correspond to hot water and 4, 5, and 6 correspond to ethanol/acetone extraction.

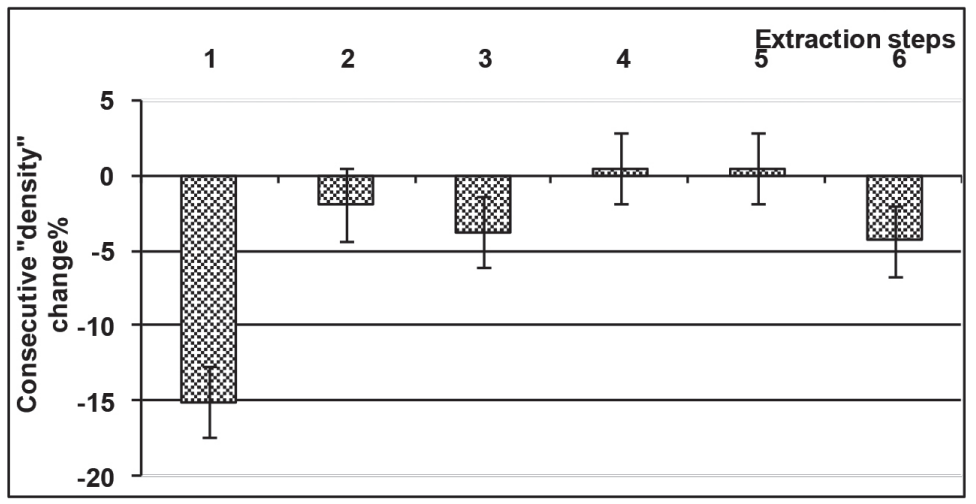

Figure 2. Consecutive density change after each consecutive extraction step. 1, 2, and 3 correspond to hot water and 4, 5, and 6 correspond to ethanol/acetone extraction. 


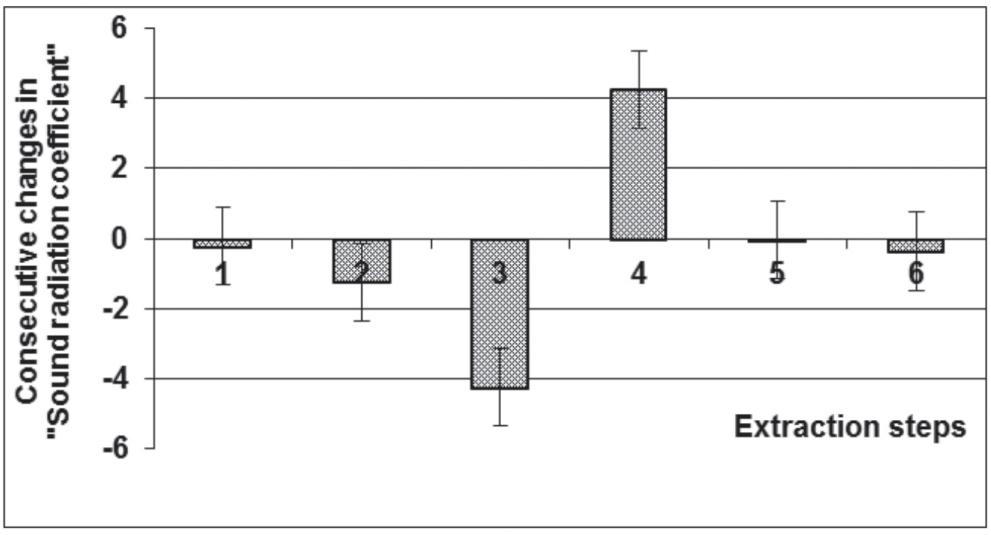

Figure 3. Consecutive changes in sound radiation coefficient after each consecutive extraction step. 1,2 , and 3 correspond to hot water and 4,5 , and 6 correspond to ethanol/acetone extraction.

Figure 4 shows a parallel behavior for damping due to internal friction. Extraction in hot water increased damping due to internal friction. These extractives were useful for acoustical property of wood. Decreases in sound radiation coefficient combined with increases in damping due to internal friction decreased the acoustical conversion efficiency (Figure 5, steps 1 to 3).

Regarding steps 4 to 6 (ethanol/acetone extraction) in the indicated figures, an inverse behavior is seen. It is understood that extractive components soluble in ethanol/acetone are not useful for acoustical property.

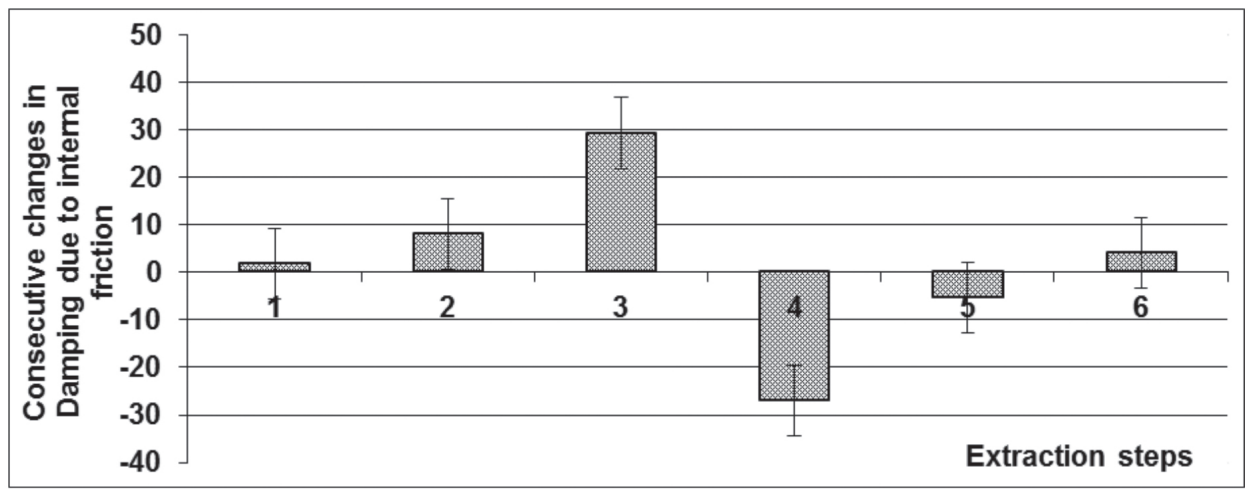

Figure 4. Consecutive changes in damping due to internal friction after each consecutive extraction step. 1,2 , and 3 correspond to hot water and 4,5 , and 6 correspond to ethanol/acetone extraction. 


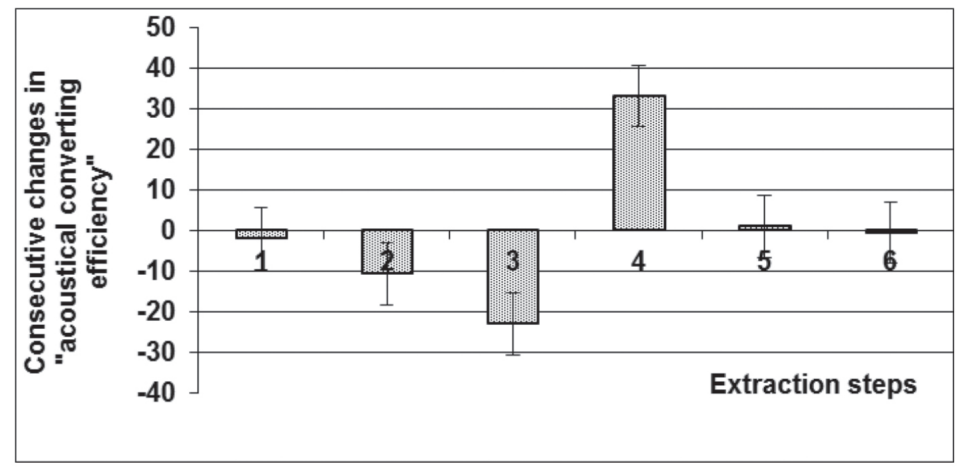

Figure 5. Consecutive changes in acoustical converting efficiency after each consecutive extraction step. 1,2 , and 3 correspond to hot water and 4, 5, and 6 correspond to ethanol/acetone extraction.

But potentially, how is Persian silk wood for musical instrument making and what happens to it after extraction in hot water and in ethanol/acetone? Figure 6 shows the material property chart for hot water extraction. Being compared to material property chart suggested by Wegst 2006, raw wood of Persian silk tree is utilizable for Violin backs and ribs before any extraction. Looking at the shifts of balloons in Figure 6, after being extracted in hot water, this species loses its potential to be used in any part of musical instrument, progressively.

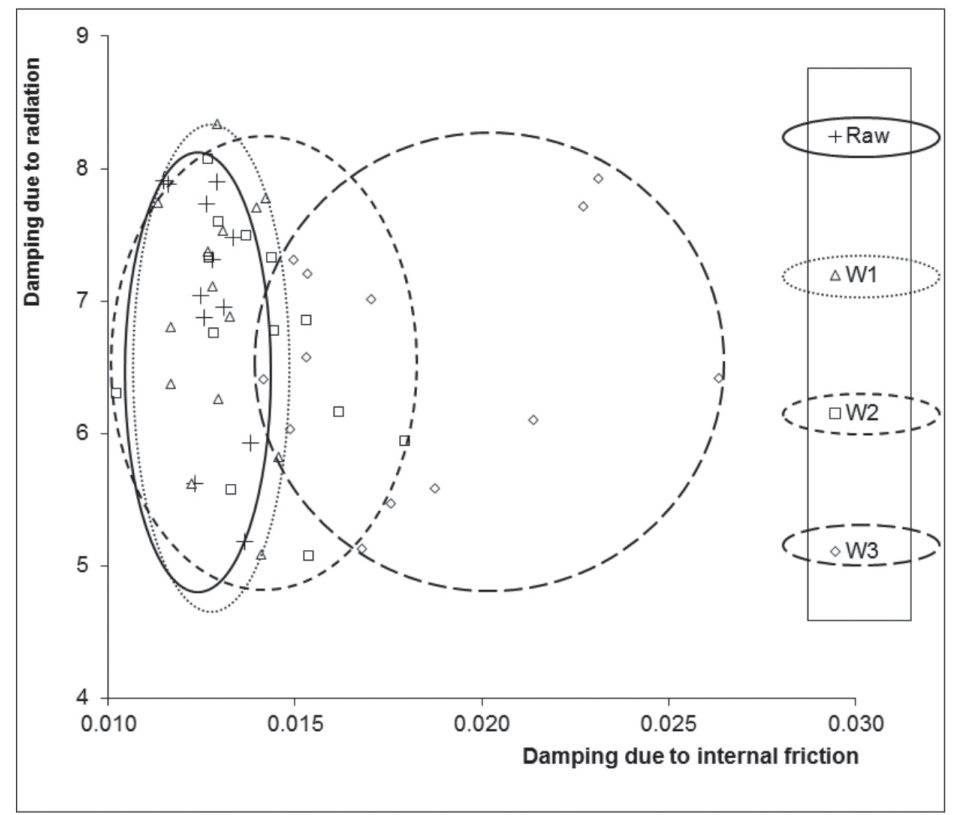

Figure 6. A material property chart for hot water extraction of Persian silk tree, plotting the sound radiation coefficient against the damping due to internal friction. W1 to 3 correspond to hot water extraction steps.

It is noteworthy to mention that all the steps of extraction and acclimatization were operated gently and because of small dimensions of the specimens, there were not any considerable concerns about the probable defects. Even the scattered data of the third step of hot water extraction was improved after ethanol/acetone extraction (Figure 7). W3 specimens after extracting the soluble components in the hot water were followed up for extracting the components soluble in ethanol/acetone mixture. Removing this portion of extractives recovered the acoustical property very similar to raw specimens (look at the shifts of balloons). It is understood that extractive components soluble in ethanol/acetone do not contribute to stiffness of the wood. 


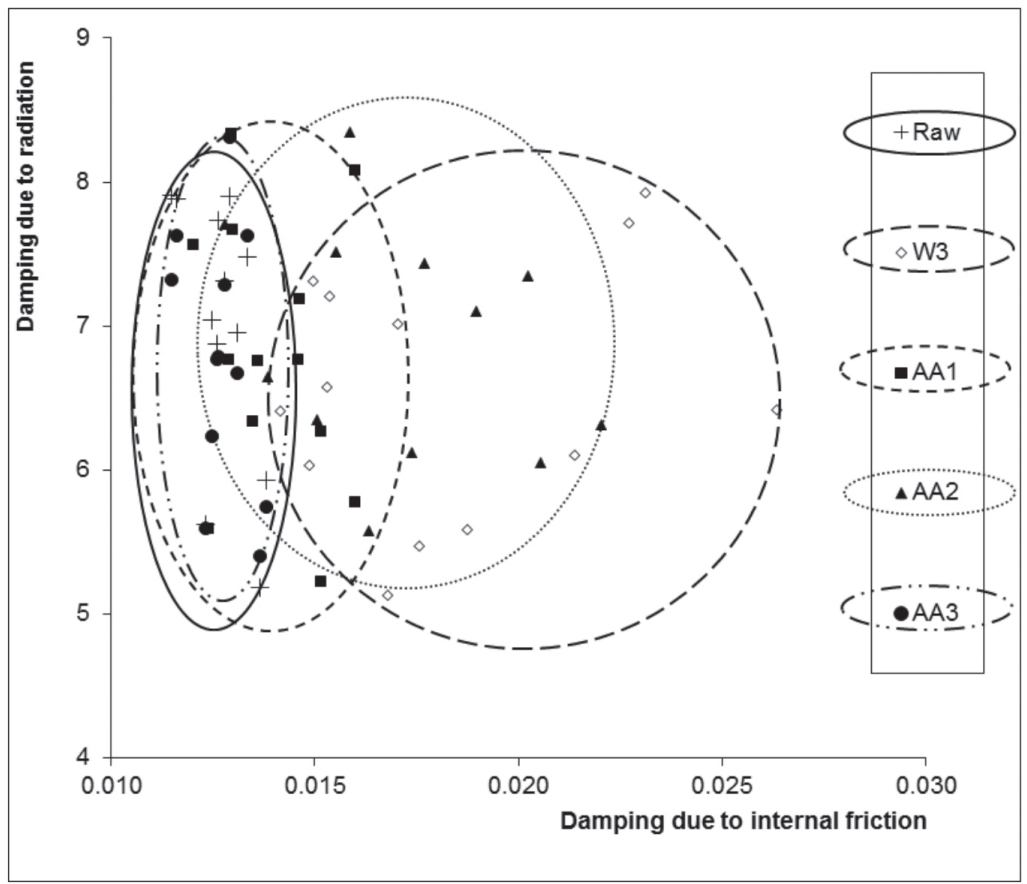

Figure 7. A material property chart for ethanol/acetone extraction of Persian silk tree, plotting the sound radiation coefficient against the damping due to internal friction. AA1 to 3 correspond to ethanol/acetone extraction steps, while raw as well as hot water extracted data are kept for comparison. 


\section{CONCLUSIONS}

Wood from Persian silk tree might play a role similar to Pernambuco in terms of effects of extractives on the acoustical property of wood. Both species are from Leguminosae family.

Extractive components soluble in hot water were positive to acoustical property while those soluble in ethanol/ acetone did not show this behavior.

Based on the suggested criteria of material property, raw wood from Persian silk tree before any extraction was located within the area of woods for violin backs and ribs.

Hot water extraction made the studied specimens useless in any part of the musical instruments. So, if this species is to be considered for instrument making, no extraction is recommended, however, ethanol/acetone extraction recovered the initial acoustical property.

\section{Further suggestions}

- It is suggested that the initiation of extraction by non-polar solvents followed by step wise increases in polarity to be formulated in future studies.

-Extractive components of this species soluble in hot water are recommended to be used to impregnate some other tone woods to examine their potential for improving the acoustical property of impregnated wood.

- Chemical components of extractives from Persian silk wood have to be identified. Which component is more efficient? Is it synthesizable in laboratory? As none of the authors of this manuscript are chemist, it is suggested to be investigated by other research teams focusing on chemical analyses and synthesis. However, there are some published literature about hot water extractives from leaves and flowers of Persian silk tree (Vaughn et al. 2007).

\section{ACKNOWLEDGEMENTS}

This manuscript is a result from the $1^{\text {st }}$ author's master thesis under the supervision of the $2^{\text {nd }}$ and $3^{\text {rd }}$ author. We thank Islamic Azad University, Karaj Branch, to support this research. 


\section{REFERENCES}

Alves, E.S.; Longui, E.L.; Amano, E. 2008. Pernambuco wood (Caesalpinia echinata) used in the manufacture of bows for string instruments. IAWA Journal 29(3): 323-335.

Bodig, J.; Jayne, B.A. 1993. Mechanics of woods and wood composites. Krieger, Malabar, FL.

Brancheriau, L.; Bailleres, H. 2002. Natural vibration analysis of clear wooden beams: a theoretical review. Wood Sci Technol 36(4): 347-365.

Brémaud, I.; Amusant, N.; Minato, K.; Gril, J.; Thibaut, B. 2010. Effect of extractives on vibrational properties of African Padauk (Pterocarpus soyauxii Taub.). Wood Sci Technol 45(3): 461-472.

Brémaud, I. 2012. Acoustical properties of wood in string instruments soundboards and tuned idiophones: Biological and cultural diversity. $J$ Acoust Soc Am 131(1): 807-818.

Matsunaga, M.; Minato, K.; Nakatsubo, F. 1999. Vibrational property changes of spruce wood by impregnation with water-soluble extractives of Pernambuco (Guilandina echinata Spreng.). J Wood Sci 45(6): 470-474.

Matsunaga, M.; Sakai, K.; Kamitakahara, H.; Minato, K.; Nakatsubo, F. 2000a. Vibrational property changes of spruce wood by impregnation with water-soluble extractives of Pernambuco (Guilandina echinata Spreng.) II. Structural analysis of extractive components. $J$ Wood Sci 46(3): 253-257.

Matsunaga, M.; Obataya, E.; Minato, K.; Nakatsubo, F. 2000b. Working mechanism of adsorbed water on the vibrational properties of wood impregnated with extractives of Pernambuco (Guilandina echinata Spreng.). $J$ Wood Sci 46(2):122-129.

Minato, K.; Sakai, K.; Matsunaga, M.; Nakatsubo, F. 1997. The vibrational properties of wood impregnated with extractives of some species of Leguminosae. Mokuzai Gakkaishi 43(12): 1035-1037.

Minato, K.; Konaka, Y.; Bremaud, I.; Suzuki, S.; Obataya, E. 2010. Extractives of muirapiranga (Brosium sp.) and its effects on the vibrational properties of wood. J Wood Sci 56(1):41-46.

Obataya, E.; Umezawa, T.; Nakatsubo, F.; Norimoto, M. 1999. The effects of water-soluble extractives on the acoustic properties of reed (Arundo donax L.). Holzforschung 53(1): 63-67.

Obataya, E.; Minato, K.; Tomita, B. 2001. Influence of moisture content on the vibrational properties of hematoxylin-impregnated wood. $J$ Wood Sci 47(4): 317-321.

Roohnia, M.; Doosthosseini, K.; Khademieslam, H.; Gril, J.; Brémaud, I. 2007. A study on variations of specific modulus of elasticity and shear moduli in Arizona cypress wood, using vibration method. Journal of the Iranian Natural Res 59(2): 921-933.

Roohnia, M.; Hashemidizaji, S.F.; Brancheriau, L.; Tajdini, A.; Hemmasi, A.H.; Manouchehri, N. 2011. Effect of soaking process in water on the acoustical property of wood for traditional musical instruments. BioResources 6(2): 2055-2065.

Roohnia, M.; Kohantorabi, M.; Tajdini, A. 2015. Maple wood extraction for a better acoustical performance. Eur J Wood Prod 73(1): 139-142. 
Rujinirun, C.; Phinyocheep, P.; Prachyabrued, W.; Laemsak, N. 2005. Chemical treatment of wood for musical instruments. Part I: Acoustically important properties of wood for ranad (Thai traditional xylophone). Wood Sci Technol 39: 77-85.

Sakai, K.; Matsunaga, M.; Minato, K.; Nakatsubo, F. 1999. Effects of impregnation of simple phenolic and natural polycyclic compounds on physical properties of wood. J Wood Sci 45(3): 227-232.

Segolpayegani, A.; Brémaud, I.; Gril, J.; Thevenon, M.F.; Pourtahmasi, K. 2012. Effect of extractions on dynamic mechanical properties of white mulberry (Morus alba). J Wood Sci 58(2): 153-162.

Sjöström, E. 1993. Wood Chemistry: Fundamentals and Applications. Academic Press limited, San Diego, Ca. p171.

Tsoumis, G. 1991. Science and Technology of wood, VanNostrand Reinold, New York. 204-207.

Vaughn, K.; McClain, C.; Carrier, D.J.; Wallace, S.; King, J.; Nagarajan, S.; Clausen, E. 2007. Effect of Albizia julibrissin water extracts on low-density lipoprotein oxidization. Journal of Agricultural and Food Chemistry 55(12):4704-4709.

Wegst, U.G.K. 2006. Wood for sound. American Journal of Botany 93(10): 1439-1448.

Yano, H.; Minato, K. 1993. Controlling the timber of wooden musical instruments by chemical modification. Wood Sci Technol 27(4):287-293.

Yasuda, R.; Minato, K. 1994. Chemical modification of wood by non-formaldehyde crosslinking reagents. Part 1. Improvement of dimensional stability and acoustic properties. Wood Sci Technol 28(3):101-110. 